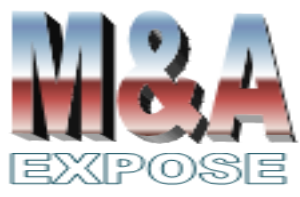

http://jurnal.usahid.ac.id/index .php/accounting
${ }^{1}$ Fakultas Ekonomi dan Bisnis Universitas Sahid wulandariendana12@amail.com annisaretno4@gmail.com

\section{Pengaruh Harga, Promosi dan Atraksi Wisata terhadap Keputusan Pembelian Tiket Universal Studio Singapore}

\author{
Endang Wulandari ${ }^{1}$, Annisa Retno Utami ${ }^{1}$
}

\section{Abstrak}

Salah satu tempat favorit wisata di Singapura adalah Universal Studio Singapore (USS) yang dibangun sejak tahun 2010 di kawasan Pulau Sentosa. Tujuan penelitian ini untuk menganalisis pengaruh harga, promosi, dan atraksi wisata terhadap keputusan pembelian tiket wahana permainan di Universal Studio Singapore (USS). Penelitian ini dilakukan pada wisatawan yang sudah pernah berkunjung ke Universal Studio Singapore (USS) dan berusia lebih dari tujuh belas tahun. Hasil penelitian menunjukkan bahwa harga, promosi dan atraksi wisata baik secara parsial maupun simultan berpengaruh positif dan signifikan terhadap keputusan pembelian tiket wahana permainan di Universal Studio Singapore (USS). Promosi merupakan variabel yang paling kuat pengaruhnya terhadap keputusan pembelian tiket wahana permainan di Universal Studio Singapore (USS), sehingga direkomendasikan agar pengelola Universal Studio Singapore (USS) semakin meningkatkan promosinya untuk meningkatkan pembelian tiket permainan para wisatawan.

Kata kunci : harga, promosi, atraksi wisata, keputusan pembelian.

\section{Abstract}

One of the favorite tourisme place in Singapore is Universal Studio Singapore (USS), which was built in 2010 in the Sentosa Island region. The purpose of this study was to analyze the effect of prices, promotions, and tourist attractions on the decision to purchase game tickets at Universal Studio Singapore (USS). This research was conducted on tourists who had visited Universal Studio Singapore (USS) and were over seventeen years old. The results showed that prices, promotions and tourist attractions both partially and simultaneously had a positive and significant effect on the decision to buy game tickets at Universal Studio Singapore (USS). Promotion is the most influential variable on the decision to buy a game ticket at Universal Studio Singapore (USS), so it is recommended that Universal Studio Singapore (USS) managers increase their promotion to increase tourist game ticket purchases.

Keywords : price, promotion, tourist attraction, decision to buy. 


\section{PENDAHULUAN}

Dalam era milineal salah satu ukuran gaya hidup seseorang bisa dilihat dari tujuan wisatanya. Dulu orang menghabiskan uangnya dengan membeli harta berupa tanah, properti, kendaraan dan perhiasan, namun seiring berjalannya waktu kebanyakan orang memilih mengkonsumsi uangnya dengan berwisata. Pariwisata menjadi bagian yang tidak dapat dipisahkan dari kehidupan karena berkaitan erat dengan kegiatan sosial dan ekonomi yang dapat dinikmati. Selain itu berwisata menjadi salah satu cara manusia dalam bersosialisasi dan melepas kejenuhan dan kepenatan dari aktivitas pekerjaan yang membosankan dan membuat lelah.

Berwisata ke luar negeri juga menjadikan pilihan banyak wisatawan Indonesia, karena dianggap lebih menarik walaupun biayanya dianggap lebih mahal. Wisata ke luar negeri yang paling dekat dengan negara kita adalah adalah ke Malaysia dan Singapura. Lazimnya wisatawan Indonesia yang pertama kali ke luar negeri berwisata ke Singapura, karena tidak membutuhkan visa dan hanya membutuhkan waktu satu jam perjalanan pesawat terbang, atau pilihan lain dengan menaiki kapal ferry selama setengah jam dari kota Batam.

Salah satu tempat favorit di Singapura adalah Universal Studio Singapore (USS) yang dibangun sejak tahun 2010, berada dalam kawasan Pulau Sentosa. Universal Studio Singapore (USS) memiliki beragam atraksi dan wahana permainan yang diperuntukan bagi segala usia. Setiap zona di dalamnya memiliki ciri khas masing-masing seperti Sci-Fi, Lost World, Far Far Away, New York, dan sebagainya.

Sejumlah penelitian sebelumnya menyatakan bahwa harga, promosi, dan atraksi wisata merupakan faktor-faktor yang berpengaruh terhadap keputusan pembelian tiket suatu objek wisata (Yuliana, 2017; Purnamasari, 2011; Anna, 2018). Sejalan dengan semakin meningkatnya iklim kompetisi antara objek wisata, maka menarik untuk menganalisis pengaruh harga, promosi, dan atraksi wisata terhadap keputusan pembelian tiket. Penelitian ini bertujuan menganalisis pengaruh harga, promosi, dan atraksi wisata terhadap keputusan pembelian tiket di Universal Studio Singapore (USS).

\section{TINJAUAN PUSTAKA}

Pariwisata. Menurut Ketut (2010), pariwisata adalah aktivitas perjalanan yang dilakukan sementara waktu dari tempat tinggal semula ke daerah tujuan dengan alasan bukan untuk menetap atau mencari nafkah melainkan hanya memenuhi rasa ingin tahu, menghabiskan waktu senggang atau libur, serta tujuan-tujuan lainnya.

Spillane (2000) mengemukakan bahwa pariwisata merupakan kegiatan dalam melakukan perjalanan dengan tujuan mendapatkan kenikmatan, mencari kepuasan, mengetahui sesuatu, memperbaiki kesehatan, menikmati olahraga atau istirahat, menunaikan tugas, berziarah, dan lain-lain. Sedangkan Arison (2008) menjelaskan bahwa pariwisata merupakan salah satu jenis industri baru yang mampu mempercepat pertumbuhan ekonomi dan penyediaan lapangan kerja, peningkatan penghasilan, standar hidup serta menstimulasi sektor-sektor produktif lainnya.

Adapun Suwantoro (2009) menyatakan bahwa pariwisata merupakan suatu perjalanan yang dilakukan oleh seseorang atau kelompok orang yang memiliki beberapa 
tujuan, di antaranya yaitu keinginan untuk mendapatkan kenikmatan dan memenuhi rasa ingin tahu terhadap sesuatu baik yang berkaitan dengan kegiatan olahraga, kegiatan konvensi, urusan keagamaan, dan keperluan untuk usaha lain.

Secara umum, definisi pariwisata adalah keseluruhan kegiatan pemerintah, dunia usaha, masyarakat untuk mengatur, mengurus dan melayani kebutuhan wisatawan. Secara teknis, pariwisata adalah rangkaian kegiatan yang dilakukan oleh manusia baik secara perorangan maupun berkelompok di dalam wilayah negara sendiri atau negara lain denggan menggunakan jasa dan faktor penunjang lainnya yang diadakan pemerintah, badan usaha dan masyarakat.

Harga. Menurut Sutopo (2016) harga merupakan suatu nilai tukar produk maupun jasa yang pada umumnya dinyatakan dalam satuan moneter. Harga menjadi penentu keberhasilan perusahaan, karena dapat menentukan seberapa besar keuntungan yang akan diperoleh perusahaan dari penjualan barang maupun jasa.

Sedangkan menurut Amstrong (2013), harga sebagai sejumlah uang yang dibebankan atas suatu barang atas jasa atau jumlah dari nilai uang yang ditukar konsumen atas manfaat-manfaat karena memiliki atau menggunakan produk jasa tersebut. Kotler (2012) menyatakan harga sebagai jumlah uang yang harus dibayar pelanggan atau konsumen untuk suatu produk.

Tiket Universal Studio Singapore (USS) dapat diperoleh secara online atau langsung beli di tempat. Harga tiket dewasa SGD81 (sekitar Rp 810.000), harga tiket anak SGD61 (sekitar Rp 610.000), dan harga tiket lanjut usia SGD43 (sekitar Rp 430.000). Harga tiket yang relatif mahal bagi kantong orang Indonesia itu menyebabkan banyak wisatawan Indonesia berkunjung hanya untuk berfoto di depan ikon Universal Studio Singapore (USS) berupa globe sangat besar bertuliskan USS.

Yuliana (2017) menyimpulkan bahwa harga berpengaruh positif signifikan terhadap keputusan berkunjung atau pembelian tiket wisata. Berdasarkan uraian tersebut maka dirumuskan hipotesis sebagai berikut :

$\mathrm{H} 1$ : Harga berpengaruh positif terhadap keputusan pembelian tiket permainan di Universal Studio Singapore (USS).

Promosi. Menurut Kotler dan Armstrong (2012), promosi merupakan kegiatan yang mengkomunikasikan manfaat dari sebuah produk dan membujuk target konsumen untuk membeli produk tersebut. Adapun menurut Hermawan (2013), promosi adalah salah satu komponen prioritas dari kegiatan pemasaran yang memberitahukan kepada konsumen bahwa perusahaan meluncurkan produk baru yang menggoda konsumen untuk melakukan kegiatan pembelian.

Beberapa promosi yang ditawarkan di Universal Studio Singapore (USS) antara lain, tiket anak gratis ice cream senilai SGD5 - SGD10, paket tiket dewasa dan voucher belanja seharga SGD35 dengan nilai voucher SGD75, tiket paket Universal Studio Singapore (USS) Pass lebih hemat 10 persen.

Purnamasari (2011) menyimpulkan bahwa promosi berpengaruh positif dan signifikan terhadap keputusan berkunjung atau pembelian tiket wisata. Berdasarkan uraian tersebut maka dirumuskan hipotesis sebagai berikut :

H2 : Promosi berpengaruh positif terhadap keputusan pembelian tiket permainan di Universal Studio Singapore (USS).

Atraksi Wisata. Menurut Witt \& Mountinho (1994) dalam Syakir, Djamhur dan Luchman (2017), atraksi wisata merupakan motivasi utama bagi para wisatawan dalam 
melakukan kegiatan kunjungan wisata. Sedangkan Suwena dan Widyatmaja (2010) mengatakan bahwa atraksi wisata adalah komponen signifikan dalam menarik wisatawan, aktrasi wisata sebagai modal utama atau sumber dari kepariwisataan. Menurut Yoeti (2000) atraksi wisata memiliki arti semua obyek atau atraksi yang tersedia sebagai daya tarik wisatawan untuk berkunjung ke tempat tersebut.

Universal Studio Singapore (USS) adalah sebuah taman bermain outdoor dan indoor yang berisi aneka atraksi berupa live show yaitu Waterworld, Monster Rock dan Madagaskar Boogie. Ada pula atraksi berupa permainan yang menarik bagi anak anak sampai dewasa atara lain Transformer, Jurasic Park, Canopy Flyier, Treasure Hunter, dan The Mummy. Hampir semua wahana ini antrian pengunjungnya berdurasi setengah sampai satu jam. Menjelang akhir jam penutupan Universal Studio Singapore (USS) terdapat pertunjukan kembang api yang cukup spektakuler dan gratis. Pengujung yang sudah keluar dari wahana Universal Studio Singapore (USS) boleh masuk lagi untuk melihat atraksi kembang api dengan memperlihatkan stempel di tangannya, yang dibubuhkan saat memasuki wahana permainan Universal Studio Singapore (USS).

Anna (2018) menyimpulkan bahwa atraksi wisata berpengaruh positif dan signifikan yang positif terhadap terhadap keputusan berkunjung atau pembelian tiket wisata. Berdasarkan uraian tersebut maka dirumuskan hipotesis sebagai berikut :

H3 : Atraksi wisata berpengaruh positif terhadap keputusan pembelian tiket permainan di Universal Studio Singapore (USS).

\section{METODE PENELITIAN}

Variabel Penelitian. Variabel yang digunakan dalam penelitian ini terdiri dari variabel-variabel berikut (Sugiyono, 2012) :

1. Variabel terikat yaitu variabel yang dipengaruhi atau menjadi akibat, karena adanya variabel bebas. Dalam penelitian ini yang menjadi variabel terikat adalah keputusan pembelian tiket $(\mathrm{Y})$.

2. Variabel bebas adalah variabel yang mempengaruhi atau yang menjadi penyebab perubahannya atau timbulnya variabel dependen. Dalam penelitian ini yang menjadi variabel bebas adalah Harga (X1), Promosi (X2) dan Atraksi Wisata (X3).

Populasi dan Sampel. Populasi merupakan gabungan dari seluruh elemen yang berbentuk peristiwa, hal atau orang yang memiliki karakteristik yang serupa yang menjadi pusat perhatian seorang peneliti yang dapat dipanjang menjadi semesta pilihan (Darmawan, 2015). Pada penelitian ini populasi mengacu pada wisatawan yang pernah berkunjung ke Universal Studio Singapore (USS).

Penentuan jumlah sampel pada penelitian ini menggunakan rumus Slovin, maka diperoleh jumlah sampel sebanyak 100 wisatawan. Dalam penelitian ini yang dijadikan sampel adalah wisatawan Indonesia yang sudah pernah mengunjungi Universal Studio Singapore (USS) dan berusia lebih dari 17 tahun.

Metode Pengumpulan Data. Penelitian ini menyebarkan 100 kuesioner kepada 100 wisatawan yang pernah mengunjungi Universal Studio Singapore (USS). Kuesioner berupa pernyataan tertutup terkait variabel Harga, Promosi, Atraksi Wisata, dan Keputusan Pembelian Tiket Permainan yang masing-masing memiliki pilihan jawaban menggunakan skala Likert. 
Uji Asumsi Klasik. Untuk memastikan bahwa model penelitian memenuhi kaidah Best Linear Unbiased Estimator, maka sebelum analisis data, dilakukan uji asumsi klasik. Uji asumsi klasik yang dilakukan dalam penelitian ini meliputi uji normalitas dengan melakukan uji one sample Kolmogorov-Smirnov, uji multikolinieritas dengan menganalisis nilai Tolerance dan Variance Inflation Factor (VIF), serta uji heterokedastisitas dengan berdasarkan diagram scatter plot.

Teknik Analisis. Teknik analisis dalam penelitian ini menggunakan analisis regresi linier berganda. Analisis ini digunakan untuk memprediksi besarnya pengaruh variabel bebas terhadap variabel terikat, dengan menggunakan persamaan :

$$
Y=a+\beta_{1} X_{1}+\beta_{2} X_{2}+\beta_{3} X_{3}
$$

Keterangan :

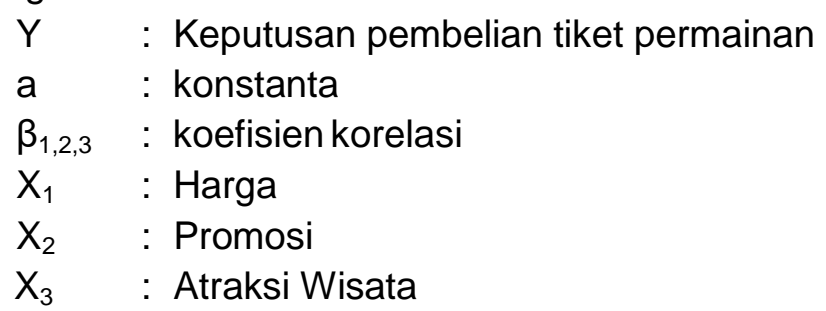

Uji Hipotesis. Uji hipotesis dalam penelitian ini menggunakan Uji t, untuk menguji signifikansi konstansta dari setiap variabel independen terhadap variabel dependen. Jika nilai $t$ suatu variabel signifikansinya lebih kecil daripada degree of freedom 0,05 maka koefisien regresi variabel tersebut adalah signifikan pengaruhnya; dan sebaliknya.

\section{HASIL DAN PEMBAHASAN}

Deskripsi Sampel. Sampel meliputi wisatawan Indonesia (domisili Jakarta) yang pernah mengunjungi Universal Studio Singapore (USS) dan berusia lebih dari 17 tahun. Jumlah sampel adalah 100 wisatawan yang terdiri dari 48 laki-laki dan 52 wisatawan wanita. Komposisi usia wisatawan pada penelitian ini yaitu usia 17-21 tahun sejumlah 48 persen, 22-26 tahun sejumlah 22 persen, 27-31 tahun persentasi 15 persen, dan lebih dari 32 tahun sejumlah 15 persen.

Hasil Uji Asumsi Klasik. Uji normalitas dilakukan dengan Uji Kolmogorov-Smirnov yang hasilnya dapat disajikan pada Tabel 1 berikut ini :

Tabel 1. Hasil Uji Normalitas

\begin{tabular}{|ll|r|}
\hline & & $\begin{array}{r}\text { Unstandardized } \\
\text { Residual }\end{array}$ \\
\hline $\mathrm{N}$ & & 100 \\
Normal Parametersa, b & Mean & .0000000 \\
& Std. Deviation & 6.40791620 \\
Most Extreme & Absolute & .069 \\
Differences & Positive & .047 \\
& Negative & -.058 \\
Kolmogorov-Smirnov Z & & .629 \\
Asymp. Sig. (2-tailed) & .726 \\
\hline
\end{tabular}


Berdasarkan hasil uji One Sample Kolmogorov-Smirnov pada Tabel 1, maka diperoleh nilai signifikansi sebesar 0,726 yaitu lebih besar daripada degree of freedom 0,05 sehingga dapat disimpulkan bahwa data berdistribusi normal.

Uji multikolinearitas dianalisis berdasarkan nilai Tolerance dan Variance Inflation Factor (VIF) sebagaimana Tabel 2 berikut :

Tabel 2. Hasil Uji Multikolinieritas

\begin{tabular}{|c|c|c|}
\hline \multirow{2}{*}{ Model } & \multicolumn{2}{|c|}{ Collinearity Statistics } \\
\cline { 2 - 3 } & Tolerance & VIF \\
\hline $\mathrm{X} 1$ & .534 & 1.593 \\
\hline $\mathrm{X} 2$ & .520 & 1.456 \\
\hline $\mathrm{X} 3$ & .566 & 1.720 \\
\hline
\end{tabular}

Sumber : data diolah, 2019.

Berdasarkan nilai Tolerance seluruh variabel independen tidak ada yang kurang dari 0,1 dan nilai Variance Inflation Factor (VIF) tidak ada yang lebih dari 10. Dengan demikian dapat disimpulkan bahwa tidak terjadi multikolinieritas antar variabel bebas pada penelitian ini.

Uji heterokedastisitas dianalisis berdasarkan diagram scatter plot sebagaimana Gambar 1 berikut. Scatter plot tidak membentuk pola tertentu sehingga dapat dikatakan tidak ada gejala heterokedastisitas.

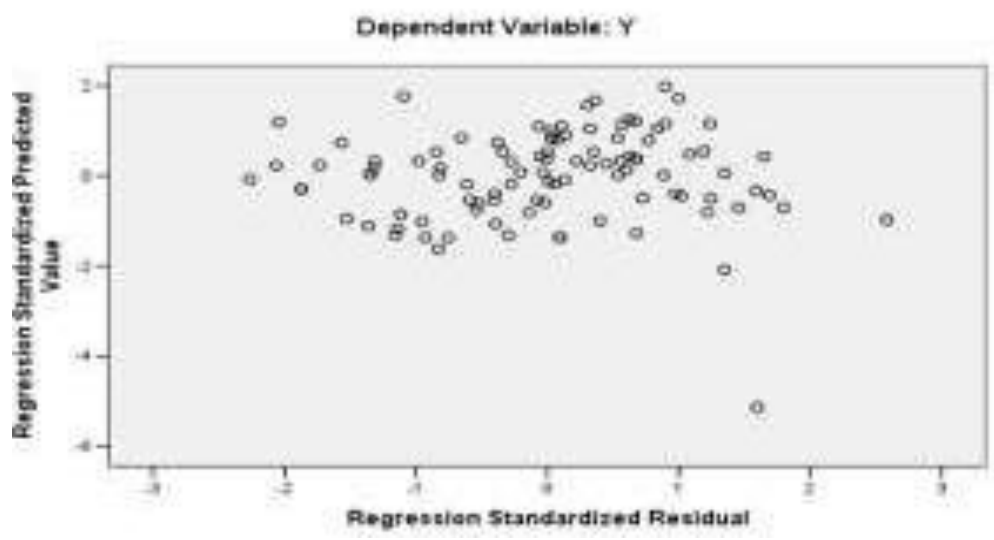

Gambar 1. Diagram Scatter Plot

Regresi Linier Berganda. Analisis regresi linier berganda digunakan untuk mengetahui besaran pengaruh variabel Harga (X1), Promosi (X2) dan Atraksi Wisata (X3) terhadap variabel Keputusan Pembelian (Y), yang disajikan pada Tabel 3 berikut :

Tabel 3. Analisis Regresi Linier Berganda

\begin{tabular}{|c|c|c|c|c|c|}
\hline \multirow{2}{*}{ Model } & \multicolumn{2}{|c|}{ Unstandardized Coefficients } & $\begin{array}{c}\text { Standardized } \\
\text { Coefficients }\end{array}$ & $\mathrm{t}$ & Sig. \\
\cline { 2 - 6 } & $\mathrm{B}$ & Std. Error & & & \\
\hline (Constanta) & .046 & 5.157 & & .005 & .786 \\
\hline $\mathrm{X} 1$ & .416 & .179 & .195 & 2.065 & .044 \\
\hline $\mathrm{X} 2$ & .617 & .194 & .413 & 5.124 & .016 \\
\hline X3 & .320 & .145 & .185 & 1.985 & .041 \\
\hline
\end{tabular}

Sumber : data primer diolah 2019 
Berdasarkan hasil Tabel 3 maka dapat disusun persamaan regresi :

$$
Y=0,046+0,416 X_{1}+0,617 X_{2}+0,320 X_{3}
$$

Persamaan tersebut menunjukkan bahwa :

1. Koefisien harga sebesar 0,416 menunjukkan pengaruh positif dan signifikan terhadap keputusan pembelian tiket permainan. Hal ini dibuktikan dengan t hitung sebesar 2,065 dengan nilai signifikansi sebesar 0,044 yang lebih kecil dari 0,05. Dengan demikian setiap perubahan harga berpengaruh signifikan terhadap keputusan pembelian tiket permainan di Universal Studio Singapore (USS).

2. Koefisien promosi sebesar 0,617 menunjukkan pengaruh positif dan signifikan terhadap keputusan pembelian tiket permainan. Hal ini dibuktikan dengan t hitung sebesar 5,124 dengan nilai signifikansi sebesar 0,016 yang lebih kecil dari 0,05. Dengan demikian setiap peningkatan promosi berpengaruh signifikan terhadap keputusan pembelian tiket permainan di Universal Studio Singapore (USS). Terdapat kecenderungan bahwa wisatawan berkunjung ke Universal Studio Singapore (USS) setelah mencermati promosi yang biasanya akan dimanfaatkan untuk mendapatkan potongan harga.

3. Koefisien atraksi wisata sebesar 0,320 menunjukkan pengaruh positif dan signifikan terhadap keputusan pembelian tiket permainan. Hal ini dibuktikan dengan $t$ hitung sebesar 1,985 dengan nilai signifikansi sebesar 0,041 yang lebih kecil dari 0,05. Dengan demikian setiap penambahan atraksi wisata berpengaruh signifikan terhadap keputusan pembelian tiket permainan di Universal Studio Singapore (USS). Biasanya jika Universal Studio Singapore (USS) merilis wahana permainan baru, maka jumlah pengunjung yang tertarik untuk datang semakin meningkat, sehingga diperlukannya inovasi dan pembaharuan atraksi wisata untuk menarik minat wisatawan untuk berkunjung.

Koefisien Determinasi $\left(\mathbf{R}^{2}\right)$. Nilai $\mathbf{R}^{2}$ dapat digunakan untuk mengetahui besaran kontribusi variasi variabel independen terhadap perubahan variabel dependen. Pada penelitian ini diperoleh hasil determinasi sebagai berikut :

Tabel 4. Koefisien Determinasi

\begin{tabular}{|c|c|c|c|}
\hline Model & $\mathrm{R}$ & R Square & Adjusted R Square \\
\hline 1 & .624 & .597 & .585 \\
\hline
\end{tabular}

Sumber : data primer diolah 2019

Berdasarkan hasil perhitungan koefisien determinasi pada Tabel 4 maka dapat diketahui bahwa $R^{2}$ sebesar 0,585. Hal tersebut berarti bahwa 58,5 persen variasi keputusan pembelian tiket permainan di Universal Studio Singapore (USS) ditentukan oleh harga, promosi, dan atraksi wisata, sedangkan sisanya sebesar 41,5 persen ditentukan oleh variabel-variabel lain di luar model penelitian ini.

\section{KESIMPULAN}

Berdasarkan hasil analisis dan pembahasan penelitian maka dapat disimpulkan sebagai berikut :

1. Analisis Regresi Linier Berganda menunjukkan bahwa Harga, Promosi dan Atraksi Wisata berpengaruh positif terhadap Keputusan Pembelian Tiket Permainan di Universal Studio Singapore (USS). 
2. Uji hipotesis menunjukkan bahwa Harga, Promosi dan Atraksi Wisata berpengaruh secara signifikan terhadap Keputusan Pembelian Tiket Permainan di Universal Studio Singapore (USS).

3. Koefisien determinasi $\left(R^{2}\right)$ menunjukkan bahwa 58,5 persen variasi keputusan pembelian tiket permainan di Universal Studio Singapore (USS) ditentukan oleh harga, promosi, dan atraksi wisata, sedangkan sisanya sebesar 41,5 persen ditentukan oleh variabel-variabel lain di luar model penelitian ini.

Berdasarkan kesimpulan tersebut, maka direkomendasikan bahwa pengelola Universal Studio Singapore (USS) lebih intensif meningkatkan program promosi karena terbukti promosi merupakan variabel yang paling besar pengaruhnya di antara ketiga variabel independen penelitian. Selain itu juga agar mengeksplorasi faktor-faktor determinan lainnya yang menentukan keputusan pembelian tiket permainan.

\section{DAFTAR PUSTAKA}

Darmawan. 2015. Metodologi Penelitian Kuantitatif. Bandung : Remaja Rosdakarya.

Hendry. 2009. Dasar-Dasar Pengertian Pariwisata.

http://mangkutak.wordpress.com/2009/01/05/dasar-pengertian-pariwisata/

Jalanjalansingapurdotcom. 2017. Liburan ke Singapura.

Kotler, Philip dan Armstrong, Gary. 2013. Prinsip-Prinsip Pemasaran. Jilid 1. Jakarta : Erlangga.

Sutanto, Rocky. 2013. Analisis Faktor-faktor yang Menjadi Pertimbangan Memilih Objek Wisata Universal Studio Singapore. Skripsi. FEB Unika Soegijapranata. Semarang.

Spilane. 2000. Siasat Ekonomi dan Rekayasa Budaya. Jakarta : Kanisius.

Sugiyono. 2012. Metodologi Penelitian Kombinasi (Mixed Method). Bandung : Alpabet.

Sutopo. 2016. Analisis Pengaruh Produk Wisata, Persepsi Harga dan Promosi terhadap Keputusan Wisatawan dalam Mengunjungi Objek Wisata.

Suwantoro, Gamal. 2009. Dasar-Dasar Pariwisata. Edisi II. Cetakan 10. Yogyakarta : Penerbit Andi.

Suwena, I Ketut. dan Widyatmaja, I Gusti Ngr. 2010. Pengetahuan Dasar IImu Pariwisata. Udayana University Press.

www.pegipegi.com, 2016. Pertama Kali ke Singapura.

Yoeti, Oka. 2000. Pemasaran Pariwisata. Cetakan pertama. Bandung: Penerbit Angkasa. 